\title{
Meet Our Editorial Board Member
}

\author{
Prof. Marco Capogna \\ Professor in Neuroscience, Department of BioMedicine \\ Wilhelm Meyers Allé 3, University of Aarhus \\ DK-8000 Aarhus \\ Denmark
}

Prof. Marco Capogna, a neuroscientist, received his PhD Degree from the University of Pisa/Zurich. He is a professor of Neuroscience in the Aarhus University and an associated member of the MRC Brain Network Dynamics Unit, Oxford and the DANDRITE Aarhus University.

His field of interest includes Neurobiology of memory, Brain circuit dysfunction in psychiatric disorders and Interneuron and GABAergic neurotransmission.

\section{SELECTED PUBLICATIONS}

[1] Bazelot, M., Bocchio, M., Kasugai, Y., Fischer, D., Ferraguti, F., Capogna, M. Hippocampal theta input to the amygdala shapes feed forward inhibition to gate heterosynaptic plasticity. This paper demonstrates that GABAergic neurons of the basal amygdala gate principal neuron firing and synaptic plasticity in the mouse amygdala. Neuron, 2015, 87, 1290-303.

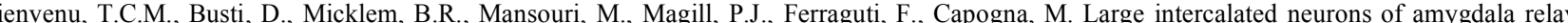
noxious sensory information. Discovery of a long-range GABAergic neuron in the amygdala projecting to cortical areas. J. Neurosci., 2015, 35(5), 2044-2057.

Bocchio, M., Fucsina, G., Oikonomidis, L., McHugh, S.B., Bannerman, D., Sharp, T., Capogna, M. Increased 5-HT transporter expression reduces fear and recruitment of parvalbumin interneurons of the amygdala. First evidence of changes in the function of a neurochemically-defined neuron type due to genetic alterations in the 5-HT transporter expression. Neuropsychopharmacology, 2015, 40, 3015-26.

Bienvenu, C.M., Busti, D., Magill, P.J., Ferraguti, F., Capogna, M. Cell type-specific recruitment of amygdala interneurons to hippocampal theta rhythm and noxious stimuli in vivo. Paper selected and recommended for F1000. http://f1000.com/prime/717950860. First comprehensive definition of GABAergic neuron types of the basolateral amygdala. Neuron, 2012, 74 (6), 1059-1074.

[5] Karayannis, T., Elfant, D., Huerta-Ocampo, I., Teki, S., Scott, R., Rusakov, D., Jones M.V., Capogna, M. Slow GABA transient and receptor desensitization shape synaptic responses evoked by hippocampal neurogliaform cells. This paper proposes a novel, non-classical mode of neuron-toneuron communication based on volume transmission of GABA. J. Neurosci., 2010, 30(29), 9898-9909.

[6] Price, C.J., Scott, R., Rusakov, D., Capogna, M. GABAB receptor modulation of feed forward inhibition through hippocampal neurogliaform cells Featured in Editors' Choice, Science. Demonstration that the GABAergic type of neuron called neurogliaform cell forms an inhibitory gate between the cortex and hippocampus to control the integration of excitatory inputs to CA1 pyramidal cells. J. Neurosci., 2008, 28 (27), 6974-6982. 